\title{
CRITICAL REVIEWS
}

\section{The Rise of Informal Logic: Essays on Argumentation, Critical Thinking, Reasoning and Politics}

\author{
BY RaLPH H. JohNSON
}

With four chapters co-authored by J. Anthony Blair. Edited by John Hoaglund, with a preface by Trudy Govier. Newport News, VA: Vale Press, 1996. Pp. xx, 1-282. Cloth U.S. \$48.65 ISBN 0916475-263. Paper U.S. \$21.45 ISBN 0916475-255.

\section{Reviewed by DAVID HitchCock}

This collection of Ralph Johnson's papers (four co-authored with J. Anthony Blair) falls naturally into four parts.

\section{A History of Informal Logic}

In the first two chapters, Johnson and Blair survey developments in informal logic. These papers, prepared for the First (1978) and Third (1989) International Symposiums on Informal Logic, are useful not only for their descriptions of texts, monographs and articles, but also for their articulation of the key questions of the field. Way back in 1978, Blair and Johnson produced an amazingly prescient list of $13 \mathrm{key}$ problem areas: theory of logical criticism, theory of argument, fallacy theory, fallacy vs. critical thinking approach, inductive/deductive distinction, ethics of argumentation and logical criticism, assumptions and missing premises, context, methods of extracting argumentation, methods of displaying arguments, pedagogy, nature and scope of informal logic, relationship of informal logic to other inquiries (27-29) [such numbers will refer to pages in the book under review]. Every one of these problem areas has been the subject of discussion in the subsequent informal logic literature, and hardly anything else has been. From the very beginning, they understood what this field was about.

For me, rereading these two chapters was a nostalgic trip. The first chapter in particular took me back to that exciting gathering in 1978 when philosophers gathered for the first time under the label "informal logic". There was a wonderful sense of something new beginning, and an unusually strong spirit of cooperation, which has continued since. 


\section{A Critique of Its Critics and Contributors}

The second part (which comes third in the book) is a critique of some of the major contributors to and critics of informal logic. Chapters 3 and 7, both written initially in 1980, critically evaluate four early influential textbooks by Kahane (1971), Thomas (1973), Scriven (1976) and Toulmin (1979). (The editor puts chapter 3 in the first part, but it belongs more naturally beside chapter 7.) Chapters 8 and 9 , both written in 1988, critically evaluate two chapters of Hamblin's classic study, Fallacies (1970): the initial chapter in which Hamblin scathingly indicts the so-called "standard treatment" of the fallacies, and the key seventh chapter on the concept of argument, in which Hamblin argues for using dialectical criteria for the evaluation of arguments rather than alethic (truth-related) or epistemic criteria. Chapter 10 , written in 1985, responds to Gerald Massey's critique (1981) of the treatment of fallacies in informal logic textbooks. Chapter 12, written in 1989, scrutinizes definitions of "critical thinking" advanced by Ennis (1987), Paul (1989), McPeck (1981), Siegel (1988) and Lipman (1988). Chapter 11, written with Tony Blair in 1990 , responds to a provocative argument by John McPeck (1991) that informal logic courses do not and cannot teach skill in argument analysis.

In these chapters, Ralph Johnson acts like a proud but anxious parent, observing carefully the achievements of major contributors to the field he has helped to create, noting strengths and weaknesses, and laying out what theoretical contributions he thinks still need to be made. He also displays for us the way in which he practices what he theorizes about: the critical examination of real argumentation in natural language. Here I find him unduly negative. My verdict reflects, I think, a difference between us about the purpose of argument analysis, a difference which Johnson nicely articulates in his review in Chapter 3 of some early informal logic texts:

The liberal approach [sc. to argument analysis] emphasizes argument as a product whose purpose is to help the human community arrive at the truth of the matter. Hence in criticizing an argument, one is justified in making changes (i.e. [sic], adding as a missing premise a statement which the arguer might not know or believe to be true) so long as those changes improve the argument and thereby its potential to arrive at the truth. The conservative approach, on the other hand, stresses the argument as the performance of the individual arguer. Hence in criticizing the argument, one is obliged to remain within the orbit of the arguer's beliefs so that the criticisms will throw light on the arguer's logical mistakes, thereby increasing the chances of a better performance by the arguer the next time out. (67-68)

This is an insightful contrast. For me, context determines which approach is appropriate. If I am grading a student's essay, I take the conservative approach, because my role is to help the student become better at constructing and presenting arguments. If I am reviewing a collection of Ralph Johnson's papers for Informal Logic, I take the liberal approach, because what is of interest to the readers of this journal is the extent to which there are meritorious contributions in Johnson's theory of argument. Of course, I will make clear where I am modifying or adding to what Johnson wrote, so that the 
reader can be clear what comes from Johnson and what is part of my tidying up of his position to put it at its best.

Johnson tends to take a conservative approach to discussing such contributions as those by Toulmin, Massey, Hamblin and McPeck. I think one could be more liberal. Thus, for all the weaknesses of Toulmin's field-dependency thesis, his concept of a warrant is a major and valuable contribution to the understanding of the macrostructure of arguments. In my view, it is the most important contribution since Aristotle distinguished premises from conclusions. And, for all he may provide inadequate support for his thesis, Massey was not far wrong in claiming in 1981 that textbook treatments of fallacy exhibit aimless thinking, exaggerated fascination with taxonomy, and shoddy reasoning. Likewise, Hamblin's critique of the standard treatment is not as far off the mark as Johnson makes it appear with his revelations of how Hamblin distorted in some respects what was in the textbooks he discussed. Further, Hamblin's argument for adopting dialectical criteria for evaluating arguments rests on a deep objection to assumptions of transcendent standards of evaluation to which the logician has privileged access. For Hamblin, there is no Platonic Idea of the good argument, so we finite human beings here on earth must make do with what pairs of us mutually agree on in back-and-forth conversation. Johnson barely recognizes this deep assumption, which to my mind is well worthy of consideration. I find it particularly odd that Johnson is so unsympathetic to Hamblin's dialectical approach to argument evaluation; Johnson himself has consistently adopted a dialectical approach, in conscious opposition to the alethic approach of formal logic texts which identify a good argument as one which is sound, in the sense of being deductively valid and having true premises. Finally, even McPeck, who has annoyingly maintained a strong field-dependency thesis in complete disregard of its repeated decisive refutation, has a point in cautioning us against overly optimistic claims for the power of general techniques of argument analysis and evaluation: many arguments do require specialized knowledge for their evaluation and even for their analysis.

\section{Johnson's Theory of Argument}

The third part (which appears second in the book) is an exposition and defence of Johnson's own position on argument and argumentation. The reader can follow the evolution of Johnson's thinking and identify his current position. Chapter 4, written for the First International Conference on Argumentation in Amsterdam in 1986 , advances a conception of an argument as an attempt to persuade an audience rationally of a contentious claim, an attempt which must therefore engage dialectically with competing positions. Chapter 5 , written with Tony Blair in 1987 , elaborates on this dialectical conception by construing an argument as the product of a process of argumentation which presupposes a challenge to the proposition being argued for. Chapter 16, written in late 1989 for a conference in February 1990 on argumentation and politics, distinguishes the structural tier and the dialectical tier of arguments, and gives criteria for each of them; this chapter in my view belongs with 
Chapters 4 through 6 rather than in the fourth part of the book. Chapter 6 , written in 1993, later than any of the other chapters, describes the benefits of adopting Johnson's pragmatic approach to argumentation and argument.

It is this third part on which I wish to focus in this review. Ralph Johnson is the cofounder and co-editor of this journal, the leading journal in the field he helped to create. He is thus severely constrained by considerations of conflict of interest in how much of his own work he can publish in it. So readers of Informal Logic may know very little of its co-editor's own thinking on the central issues of informal logic. I think it's time they found out. So I shall extract the most recent positions expressed in this book, and raise some critical and clarificatory questions about them.

\section{Theory of argument}

Johnson conceives of an argument pragmatically. It is a discourse by which someone tries to persuade an audience rationally to accept some thesis. To advance an argument is to reply to a question or doubt about some proposition. This proposition is thus controversial or disputed; others will have incompatible views, and will be disposed to raise certain objections to the argument advanced.

This limitation of the concept of argument strikes me as problematic. How are we to decide on a definition of "argument"? To some extent we are free to stipulate whatever boundaries we like for the application of the term, as long as we stick to our stipulation and are not so idiosyncratic that we confuse our audience. To some extent we should conform to existing usage. And to some extent we should be concerned that it is theoretically fruitful to mark off just the class of objects we designate by this term, that there are generalizations which apply to all and only the objects so demarcated.

As to existing usage, the word "argument" in English has an unfortunate ambiguity between two concepts: (1) a claim-reason complex, usually asserted for the purpose of showing that the claim deserves acceptance; (2) an extended verbal disagreement. Other languages use different words for these two concepts: classical Greek logos vs. antilogia, Russian argument vs spor, French argument vs. discussion, etc. I suspect that Johnson has been misled by the ambiguities of English usage into thinking that every actual claim-reason complex (as opposed to the silly invented examples found in formal logic texts) arises in the context of a verbal disagreement. Hence his insistence that verbal reasonings to oneself (e.g. working out what to do in order to accomplish some objective) or products of inquiry (e.g. drawing conclusions from the reported results of an experiment or systematic observation) are not arguments. At one point in the book ( 86 , notes 7 and 8 ) Johnson accepts the urging of his critics that not all arguments are directed at rational persuasion, some being reports of inquiries. But later (106) he treats uses of argument for inquiry, reinforcement of existing belief and similar purposes as derivative from its use to persuade others. This claim requires support. I for one doubt it. 
Johnson might wish to give a theoretical justification for restricting "argument" as he does. He could point out that in the texts he calls "arguments", but not in other claim-reason complexes, there is or should be a second tier of communication in which the author of the argument deals with competing arguments. True enough. But the first-tier criteria are the same for all claim-reason complexes (except that reasons which are merely supposed for the sake of the argument do not need to be acceptable). So on theoretical grounds it seems reasonable to lump all claim-reason complexes together under one label, and to mark off as a proper species of this genus those claim-reason complexes which are advanced in a context of verbal disagreement about the claim. I personally don't care what labels are used for the genus and the species, as long as the terminology confuses nobody. In fact, in a lengthy endnote to the most recently written chapter in this collection, Johnson seems to label the genus as giving reasons, and to distinguish as species arguing, explaining, instructing, making an excuse, and giving a reason for a course of action (112-113, note 7). Alternatively, one could call the genus "argument" and the species with the dialectical tier something like "dialectical argument" or "controversy-oriented argument".

At any rate, on Johnson's conception, arguments are only the first tier of a complex process, or practice, of argumentation. The author of an argument has not only the obligation to provide direct support for the thesis advanced, but also the obligation in a second, dialectical tier to defuse likely objections. Each of these tiers has its own criteria of evaluation.

\section{First tier: acceptability?}

As for the first tier, in his early work Johnson joined Blair in identifying three individually necessary and jointly sufficient conditions for adequacy: acceptability of each premise, relevance of each premise, and sufficiency of the combination of the premises.

In a chapter co-authored with Blair in 1987, Johnson identifies the acceptability of a premise with the willingness of an ideal audience to grant it, namely, the community of ideal interlocutors with respect to that proposition, interlocutors who are knowledgeable, reflective, open and dialectically astute (94-98). But this construction appears at only one other place in the collection ( 268 , note 5 , which appears to have no anchor in the text). I speculate that it comes from Blair, and was never really part of Johnson's theory of premise-adequacy. In the most recent edition of their textbook, Johnson and Blair construe the acceptability of a premise as its being reasonable to expect a member of the audience to take the premise without further support (1993: $314,62-64)$. Being common knowledge among the audience is a sufficient condition for being acceptable.

Apparently because of his critique of Hamblin's dialectical criteria, Johnson himself has become uneasy with acceptance and even acceptability as criteria for premiseadequacy; he now wants something stronger than acceptability but weaker than truth (264). It's not clear to me why. Johnson's objections to Hamblin raise difficulties for 
using actual acceptance by one's interlocutor as a criterion of premise adequacy, but not, it seems, for using the reasonableness of audience acceptance.

Further, acceptability is not always a weaker criterion than truth: while there are propositions which are acceptable but not true, there are also propositions which are true but not acceptable, for example one or other of the propositions that Goldbach's conjecture (that every even number is the sum of two primes) is true and that it is false. At the moment, the conjecture has neither been proved nor refuted, but it must be either true or false.

In fact, if one takes seriously Johnson's conception of rational persuasion as the goal of argumentation, then it seems to me that one would want to strengthen the criterion of acceptability in a different direction, namely, by adding a requirement that the audience accept the premise, or be amenable to accepting it. For an audience will not be rationally persuaded by an argument if it neither accepts nor can be brought to accept a necessary premise, even if it would be reasonable for them to accept it. Thus, if I adopted Johnson's view of the function of argument, I would be inclined to take as the criterion of premise-adequacy that the intended audience of the argument have good reason to accept the premise and either actually accept it or be brought by the argument to accept it.

\section{First tier: relevance}

On the second condition, relevance, Johnson reports (264) a change in his position from treating relevance as an all-or-nothing property to treating relevance as a matter of degree. He seems to want to change the requirement that each premise be relevant to a requirement that it be relevant enough. But nowhere in this collection does there seem to be any explication of what he means by relevance. We can, however, extract a conception of the relevance of a premise $P$ to a conclusion $C$ from the most recent edition of Johnson and Blair's textbook:

Suppose $P$ is true; does that increase the likelihood of $C$ being true? No... Does $P$ 's truth increase the likelihood of $C$ 's falsehood? Not at all... Now suppose $P$ were false; what difference would that make to $C$ 's truth value? ... [None.] The truth and falsehood of $P$ and $C$, then, are totally independent; hence $P$ is irrelevant to $C$. (1993:55)

The final argument clearly assumes that:

If the truth and falsehood of $P$ and $C$ are totally independent, then $P$ is irrelevant to $C$.

And it is reasonable to attribute to them the converse position:

If $P$ is irrelevant to $C$, then the truth and falsehood of $P$ and $C$ are totally independent.

They make clear that the independence in question is independence given the other premises simultaneously offered in support of $C$. Putting all these pieces together, we can reconstruct Johnson and Blair's (1993) conception of premise relevance as follows: 
A premise $P$ in an argument is relevant to the conclusion $C=$ in the context of the other premises of the argument, either the truth or the falsehood of $P$ changes the likelihood that $C$ is true.

We can express this conception in terms of conditional probabilities, where prob $(C$, $P$ ) is the probability that $C$ is true given that $P$ is true, and $Q$ is the conjunction of the other premises of the argument:

A premise $P$ in an argument with additional premises $Q$ is relevant to the conclusion $C=\operatorname{prob}(C, P \& Q) \neq \operatorname{prob}(C, Q)$ or $\operatorname{prob}(C$, not $P \& Q) \neq$ $\operatorname{prob}(C, Q)$

A plausible explication of the probabilities mentioned is that they are epistemic probabilities, relative to the background knowledge, either at the time $P$ and $C$ are asserted or at the time the relevance of $P$ to $C$ is assessed, of the person judging whether $P$ is relevant to $C$. (Note that, following a liberal strategy of argument analysis, I have elaborated on the text's partial explication of a theory of relevance.)

Woods (1994) has raised two difficulties for such an account of relevance in terms of conditional probabilities. First, it does not permit determination of relevance in some cases where we would want to determine relevance. For example, if $P$ is a contradiction, the first disjunct in the definition of relevance cannot be computed and the second disjunct is false, even when $P$ is in fact relevant to $C$ (as would be the case if $P$ were "A and not A" and $C$ were " $\mathrm{A}$ "); or if $P$ is $C$, in which case the conditional probabilities (Woods claims) cannot be computed. Second, there is the problem (common to Bayesian approaches to induction) of computing the prior probability of $C$ given $Q$. The unsolved problem for Bayesians is computing the probability of a proposition $C$ prior to any evidence bearing on it; such a computation is necessary in order to start the process of changing conditional probabilities as relevant evidence accumulates.

Aside from these two difficulties which Woods raises, there are obvious counterexamples to the Johnson-Blair conception of premise relevance. Some of these are cases where intuitively a premise is relevant, but on the definition it comes out irrelevant. Imagine that the status of a child's stuffed toy, "Ben," is disputed, and the child argues:

All cats are animals. Ben is a cat. So Ben is an animal.

The first premise seems relevant. But the probability that Ben is an animal, given that Ben is a cat, is 1 . And so is the probability that Ben is an animal, given both premises. So according to the definition the first premise is irrelevant.

Again, consider someone filling out an income tax return and trying to decide whether it is possible to claim daughter Jane as a dependent. The general rule, let us suppose, is as follows:

A person can claim their own child as a dependent for income tax purposes if during the year in question the child either is under 19 or is under 25 and is registered as a full-time student at a post-secondary institution.

The taxpayer says to Jane, who insists that she cannot be claimed as a dependent: 
I can claim you as a dependent. You are 18. You are my child. And you are registered as a full-time student at a post-secondary institution.

The last premise seems relevant. But the probability of the conclusion given the premises is 1, whether or not you include the last premise. So on the Johnson-Blair conception the last premise is irrelevant.

Another sort of counter-example is an argument where a premise seems irrelevant but counts as relevant on the Johnson-Blair conception. Suppose a dispute arises over whether the Smiths are going to go ahead with the picnic they had planned. Someone says:

The Smiths were really looking forward to their picnic today. But there's a torrential downpour outside which is not going to let up. So probably they will cancel the picnic.

Here the first sentence sounds like a concessive remark, irrelevant to the conclusion and therefore not counted as a premise. But on the Blair-Johnson account it would be relevant, since the conclusion is slightly less probable given both pieces of information than it is given just the second one.

A third sort of counter-example is an argument with a non-factual conclusion. Suppose a father is thinking of telling his son Johnny that Johnny will never make a good piano player. Johnny's mother objects:

You shouldn't tell Johnny that he will never make a good piano player. It's not true, and he would be very hurt if you told him that.

Does the second premise change the conditional probability of the conclusion? Does it make sense in the first place to assign probabilities to "should" statements?

Further, if Johnson is willing to construe relevance as making a difference to a conclusion's conditional probability, how is his treatment of it as a matter of degree to be explicated? One suggestion that occurs to me is the following:

$R$ is more relevant than $P$ to $C=|\operatorname{Prob}(C, R \& Q)-\operatorname{Prob}(C, Q)|>\mid \operatorname{Prob}(\mathrm{C}$, $\operatorname{P} \& Q)-\operatorname{Prob}(C, Q) \mid$ or $|\operatorname{Prob}(C, R \& Q)-\operatorname{Prob}(C, Q)|>\mid \operatorname{Prob}(\mathrm{C}$, not P \&

$Q)$ - Prob $(C, Q) \mid$ or $|\operatorname{Prob}(C, \operatorname{not} R \& Q)-\operatorname{Prob}(C, Q)|>\mid \operatorname{Prob}(\mathrm{C}, \operatorname{P} \& Q)$

- $\operatorname{Prob}(C, Q) \mid$ or $|\operatorname{Prob}(C, \operatorname{not} R \& Q)-\operatorname{Prob}(C, Q)|>\mid \operatorname{Prob}(\mathrm{C}, \operatorname{not} \mathrm{P} \& Q)$

- $\operatorname{Prob}(C, Q) \mid$.

Would Johnson accept this suggestion? If so, many questions arise. In the example of the wife trying to dissuade her husband from telling their son he will never make a good piano player, which of the two premises is more relevant to the conclusion? How are we to make such a calculation? Or consider the following argument:

A composite object is liable to break up. It is extremely probable that what is inconstant and variable is composite. The members of a class corresponding to an absolute entity like beauty or equality are inconstant and never free from variation. So probably any member of a class corresponding to an absolute entity like beauty or equality is liable to break up. (Paraphrase of Plato, Phaedo 78c-e.) 
Each of the three premises is needed for the derivation of the conclusion. Can we compute the comparative contribution of each of them to raising the probability of the conclusion? Which of them is most relevant? Which is least relevant? Or are they all equal in relevance? Some clarification is needed.

Johnson may respond to this series of sceptical questions by rejecting the interpretation of "increase the likelihood" in terms of conditional probabilities. If so, he owes his readers an alternative explication.

Aside from the problem of explicating the concept, I would raise the further question whether relevance of each premise is really a necessary condition for argument adequacy. Suppose an argument meets the condition for premise adequacy (whatever that is) and its premises provide sufficient support for its conclusion (however sufficiency is understood), but it has an irrelevant premise. Does that make it a bad argument? Inelegant, maybe. But, if the purpose of an argument is to persuade its audience rationally to accept the conclusion, aren't premise adequacy and sufficiency enough? On Johnson's view, you can change a good argument into a bad one just by adding an irrelevant premise. Does he accept this consequence? Of course, at least one premise of a good argument must be relevant to its conclusion. But this condition is a consequence of sufficiency, and does not need to be added as a separate condition.

\section{First tier: sufficiency}

As for sufficiency, it is a truism that the premises of a good argument must together provide enough support to make acceptance of the conclusion on the basis of the premises rational (assuming the premises are adequate). The key question is: How much support is enough? Johnson makes the puzzling statement in this collection that how well a premise-set meets the sufficiency requirement is a matter of degree (264). Taken at face value, this statement means that one set of premises can provide more enough support for its conclusion than another set of premises does for its conclusion. But "more enough" is ungrammatical. Johnson's readers need an explanation.

In the most recent edition of their textbook, Johnson and Blair propose the following necessary condition for a fair challenge of insufficiency:

...the evidence advanced in an argument can be challenged fairly as insufficient [when and?] only when the critic can cite some item of relevant evidence that would make a difference to the verdict and that has not been taken into account in the argument. (1993: 60-61)

But this seems obviously false. Suppose someone argues that capital punishment is a deterrent on the ground that prisoners sentenced to death generally use all possible legal avenues to try to get their sentence commuted. A critic can fairly challenge the premise as insufficient simply by pointing out that the question at issue is not whether the prospect of the death penalty for a given crime will tend to discourage that crime, but whether it will do so more than the likely alternative penalty, say life imprisonment with a substantial minimum period in jail before eligibility 
for parole. The fact that people will try to avoid being executed is not enough to prove differential deterrence; one would need to show that they won't try, or won't try nearly as hard, to avoid being sentenced to life imprisonment. It is not necessary for the critic who points this out to cite some item of relevant evidence, not taken into account in the argument, whose addition to the premise-set would produce an argument which would undermine the claim that capital punishment is a deterrent.

In fact, in their textbook, Johnson and Blair give examples of insufficient premises which are relativized to the type of argument. Thus, anecdotal evidence is insufficient support for a generalization; the evidence needs to be systematic. So is an unrepresentative sample; here more evidence of the same kind is needed. A premise-set which ignores actual or possible contrary evidence is insufficient (1993:56-58). Appealing to a new practice to show that values and expectations have changed is not enough; one must also show that the new practice has become established (1993:120). The mere existence of a before-and-after sequence is not enough to support a causal claim; one must also rule out other plausible explanations (1993: 124). The force of the sufficiency condition, it seems to me, comes in how it is cashed out for each such specific type of argument. It does not seem necessary in any of these specific cases to cite omitted relevant evidence that would make a difference to the verdict.

One question which arises about sufficiency is whether it is an absolute or a relative concept. If a given set of premises provides sufficient support for the conclusion when the argument is addressed in a particular context to a particular audience, does it also provide sufficient support in any other context or with any other audience? Or does the threshold of sufficiency change with context and audience? If so, on what principles? How do we tell in any given case how much support is enough? (Note that Bayesians have a principled answer to this question, whereas nobody else seems to. Bayesians can, for example, evaluate in a principled way the reasonableness of the distinction made in the Anglo-American legal tradition between the standard of proof required in criminal trials and the standard of proof required in civil cases. I know of no other principled basis for such an evaluation.)

\section{Second tier: dialectical criteria}

The second tier of argumentation is a distinctive contribution of Johnson. Here I think he makes a genuine advance on even such avowedly dialectical contributions as those of Hamblin (1970), Rescher (1977), Barth and Krabbe (1982) and van Eemeren and Grootendorst $(1984,1992)$. For, although all these theorists conceive of argumentation as a back-and-forth conversational interchange, the arguments which get built up in such an interchange belong solely to Johnson's first tier. Johnson is surely right to hold that, when one attempts to persuade an audience rationally of a hotly contested thesis, one must not only give direct arguments for the thesis, but must also rebut or defuse the objections which are likely to come from those who hold incompatible positions on the issue. In their textbook Johnson and Blair refer to a global sufficiency requirement: 
You must ... respond to the competing points of view on the issue, and to the reasons why others might resist your conclusion... An argument which does not in some sense address these competing points of view fails to satisfy the requirement of global sufficiency. (1993:61)

In a co-authored chapter in the present collection written in 1987, Johnson and Blair take the community of model interlocutors as their basis for determining what objections to the premises, to the connection between premises and conclusion, and to the conclusion itself need to be taken into account (100-101). But, as I mentioned under "acceptability", the later writings in this collection contain only a passing unanchored reference to the concept of the model interlocutor (268, note 5). In that chapter, written in late 1989 , Johnson lists three respects in which an argument must be dialectically sufficient. It must address itself to alternative positions, it must deal with objections, and it must handle consequences. The question of how to determine which alternative positions, objections and consequences to discuss, and to what extent, is an open problem.

\section{Theory of criticism}

For Johnson, informal logic includes not only the theory of argument and the theory of argumentation but also the theory of argument criticism. This theory investigates the norms of criticizing arguments: To what principles should the criticism of an argument adhere? Although none of the chapters in this collection addresses this question centrally, Johnson does endorse in passing three principles: the principle of charity, the principle of discrimination and the principle of logical neutrality. I shall propose to add a fourth.

\section{Principle of charity}

The principle of charity was first applied to argument criticism by Rescher (1964), who appealed to it as a constraint on supplying missing premises. In "Charity Begins At Home" (1981), unfortunately not included in the present collection, Johnson articulates it as the principle that the critic should make the best possible interpretation of the material under consideration, and recognizes that it has many applications. But he objects to widening the principle so as to license producing a better argument than the one which is actually in the text; generosity so ample is for him not charity, but welfare. In terms of his own distinction, he clearly takes a conservative approach to argument criticism, whereas I am more inclined (depending on context) to take a liberal approach. Is there a right and a wrong about this difference? How would Johnson defend his stringency against the more liberal approach to charity which I favour? What exactly is wrong with welfare? (In the social context from which this metaphor is borrowed, I think welfare is a great idea, as long as it does not foster dependency but on the contrary helps people to become independent and self-supporting. What's wrong with helping somebody else out when for one reason or another they are not managing very well on their own? Especially when, in the context of argument criti- 
cism, the helper might learn something new from the exercise?) How exactly would Johnson formulate his restricted version of the principle of charity? And would he apply it to all the dimensions of argument criticism to which Govier (1987) applies it: determination of whether a text is an argument, determination of which assertions in the text are constituents of the argument, clarification of the propositional content of each such assertion, attribution of implicit assumptions to the argument, choice of a standard of inference appraisal?

\section{Principle of fairness}

Even prior to the principle of charity in argument criticism, it seems to me, is a principle rarely articulated by informal logicians: the principle of faimess. Faimess demands that an argumentative text not be distorted to make it seem worse than it actually is. Such distortions are common in argument criticism in dialectically charged contexts; they commit the straw man fallacy. (Note: I use "straw man" rather than "straw person" because it is less awkward and is disrespectful to neither sex.)

\section{Principle of discrimination}

The principle of discrimination comes from Scriven, who says (1976: 184) that we should produce criticism which "goes to the heart of the argument" and which shows that the argument failed there rather than in some peripheral place. "This principle," writes Johnson, "lies at the core of effective criticism" (65). I agree; we are all familiar with the weakness of marshalling nit-picking objections which the arguer can handle with a slight modification of the argument. That's why I generally favour a more liberal approach to argument criticism, with a generous principle of charity: Get the slips of the pen and the repairable vagueness and ambiguity out of the way, so you can get down to what's central in the argument. How, I wonder, can Johnson reconcile his endorsement of the principle of discrimination with his conservative approach to argument criticism and his grudging conception of charity?

\section{Principle of logical neutrality}

The principle of logical neutrality "prohibits the critic from seeking to pass off substantive criticism as if it were logical criticism" (267). About this principle I have reservations. Not that I think it is all right to pass off substantive criticism as if it were logical criticism. Rather, I question the presupposition that criticism can be neatly divided into the substantive and the logical. The fallacy of suppressing important relevant evidence, common in undergraduate essays, is at once a logical mistake and a substantive error. The post hoc fallacy of inferring a causal connection from mere correlation or sequence is a logical mistake, but convicting someone of committing the fallacy depends on making substantive assumptions about the absence of unstated evidence for a causal mechanism linking the two variables or events mentioned in the argument. The straw man fallacy is in some sense a "logical" mistake, but making the 
charge stick depends on substantive knowledge about what the author of the position being attacked actually said, wrote or thought. And so on. It is instructive, for example, to compare Bentham's list of political fallacies in his handbook (1962/1824) with that of C. D. Broad (1950). Bentham, who was a political reformer, includes in his list only fallacies committed by those who are resisting proposals for change. Broad, who was clearly not a reformer, includes in his list only fallacies committed by those who are advocating change. Each author makes an assumption about where the burden of proof lies; for Bentham, it lies with the defender of tradition and opponent of change, while for Broad it lies with the advocate of change from traditional ways of doing things. It is both a logical question and a highly-charged substantive political question where the burden of proof lies in such argumentative contexts, and how strong a burden it is. My own view is that, in contexts where the present state of affairs is not desperate, there is a substantial but not overwhelming burden of proof on the reformer to show that, all things considered, the proposed reform is likely to result in a better state of affairs than the continuation of the present system would produce. This position is both a logical and a substantive one, it seems to me. I would be interested in how Johnson would respond to this suggestion about the burden of proof on political reformers, and under what heading he would classify it.

In Johnson's principle of logical neutrality I detect the suggestion that argument criticism should confine itself to logical criticism. But that is to propose an unfortunate abstraction of logical form from substantive content. In our everyday production and consumption of arguments, we are whole human beings, concerned about both substantive and logical questions. The theory and practice of argument criticism should match the wholeness which we manifest in our untutored critical practices. Techniques of argument criticism, such as the commonly recognized fallacies, are often mere schemas whose application to particular cases requires substantive knowledge and substantive judgment, including value judgment. In the pedagogical context, as teachers of informal logic, we need to caution our students against a merely schematic deployment of the quasi-technical vocabulary of argument criticism. Concepts of premise adequacy, sufficiency of support and fallacy should be used as means for enhancing engagement with the substance of the arguments our students examine, not as a substitute for such engagement.

\section{Other principles?}

I have discussed the principles of charity, of faimess, of discrimination and of logical neutrality. Nowhere have I detected a claim by Johnson that this list is exhaustive. Would he wish to add any other principles to the theory of argument criticism? 


\section{Boundary Problems}

In the fourth part of the book, Johnson discusses the relationship between argumentation, inference and reasoning (chapter 13, written in 1987-88); reasoning, critical thinking and informal logic (chapter 14, written in 1989); and informal logic, reasoning and argumentation (chapter 15, written in 1993). I find the taxonomic and programmatic questions in these papers of little interest, and so shall ignore them.

\section{Codas}

The book has two substantial drawbacks. It lacks an index, which makes it impossible for a reader to locate the places where Johnson talks about some particular topic. And it buries and in some cases omits information about the dates when Johnson composed the chapters. For the benefit of the reader who may want to trace the development of Johnson's ideas, here are the dates Ralph Johnson communicated to me (chapter number, followed by "B" if co-authored with J. Anthony Blair, with year of composition of first draft in parentheses): $1 B(1978), 7$ and 3 (1980), 10 (1985), 4 (1986), 5B (1987), 13 (1987-88), 8 and 9 (1988), 2B (1988-89), 14 (early 1989), 12 (mid 1989), 16 (1989-90), 11B (1990), 15 (early 1993), 6 (late 1993).

Because of the length of this review, the book review editor has decided not to allow Ralph Johnson to reply in this same issue. The decision is understandable but regrettable, because I have raised many questions to which I (and I think others) would like to hear Johnson's answers. I hope we have an opportunity to hear them in some forum soon.

\section{References}

Barth, E. M., and E. C. W. Krabbe. 1982. From Axiom to Dialogue. Berlin: De Gruyter. Bentham, Jeremy. 1962/1824. Handbook of Political Fallacies. New York: Harper.

Broad,C.D. 1950. "Some Common Fallacies in Political Thinking." Philosophy 25: 99-113.

Eemeren, Frans H. van, and Rob Grootendorst. 1984. Speech Acts in Argumentative Discussions. Dordrecht: Foris.

Eemeren, Frans H. van, and Rob Grootendorst. 1992. Argumentation, Communication, and Fallacies. Hillsdale, NJ: Lawrence Erlbaum.

Ennis, Robert H. 1987. "A Taxonomy of Critical Thinking Dispositions and Abilities". In J. B. Baron and R. J. Sternberg, eds., Teaching Thinking Skills: Theory and Practice. 9-26. New York: Freeman.

Govier, Trudy. 1987. Problems in Argument Analysis and Evaluation. Dordrecht: Foris. Hamblin, C.L. 1970. Fallacies. London: Methuen.

Johnson, Ralph H.1981. "Charity Begins at Home." Informal Logic Newsletter 3, 2( June): 49.

Johnson, Ralph H. and J. Anthony Blair. 1993. Logical Self-Defense, Third Edition. Toronto: McGraw-Hill Ryerson. 
Kahane, Howard. 1971. Logic and Contemporary Rhetoric: The Use of Reason in Everyday Life. Belmont, California: Wadsworth.

Lipman, Matthew. 1988. "Critical Thinking: What Can It Be?" Analytic Teaching 8: 5-12.

Massey, Gerald. 1981. "The Fallacy Behind Fallacies." Midwest Studies in Philosophy 6:489500.

McPeck, John. 1981. Critical Thinking and Education. New York: St. Martin's.

McPeck, John. 1991. "What Is Learned in Informal Logic Courses?" Teaching Philosophy 14: 25-34.

Paul, Richard. 1989. "Critical Thinking in North America: A New Theory of Knowledge, Learning and Literacy." Argumentation 3: 197-235.

Rescher, Nicholas. 1964. Introduction to Logic. New York: St. Martin's.

Rescher, Nicholas. 1977. Dialectics: A Controversy-Oriented Approach to the Theory of Knowledge. Albany: SUNY Press.

Scriven, Michael. 1976. Reasoning. New York: McGraw-Hill.

Siegel, Harvey. Educating Reason: Rationality, Critical Thinking and Education. New York: Routledge.

Thomas, Stephen N. 1973. Practical Reasoning in Natural Language. Englewood Cliffs, NJ: Prentice-Hall.

Toulmin, Stephen, Richard Reike and Allan Janik. 1979. An Iniroduction to Reasoning. New York: Macmillan.

Woods, John. 1994. "Sunny Prospects for Relevance?" In Ralph H. Johnson and J. Anthony Blair, eds., New Essays in Informal Logic. 82-92. Windsor, ON: Informal Logic.

DAVID HITCHCOCK DEPARTMENT OF PHILOSOPHY, MCMASTER UNIVERSITY HAMILTON, ON L8S 4KI 